\title{
A decision analysis framework for stakeholder involvement and learning in groundwater management
}

\author{
T. P. Karjalainen ${ }^{1}$, P. M. Rossi ${ }^{2}$, P. Ala-aho ${ }^{2}$, R. Eskelinen ${ }^{2}$, K. Reinikainen ${ }^{3}$, B. Kløve ${ }^{2}$, M. Pulido-Velazquez ${ }^{4}$, and \\ H. Yang ${ }^{5,6}$ \\ ${ }^{1}$ Thule Institute, University of Oulu, P.O. Box 7300, University of Oulu, 90014 Oulu, Finland \\ ${ }^{2}$ University of Oulu, Department of Process and Environmental Engineering, Water Resources and Environmental \\ Engineering Laboratory, P.O. Box 4300, University of Oulu, 90014 Oulu, Finland \\ ${ }^{3}$ Pöyry Finland Oy, Tutkijantie 2A-D, 90590 Oulu, Finland \\ ${ }^{4}$ Research Institute of Water and Environmental Engineering, Universitat Politècnica de València, Camino de Vera s/n, \\ 46022 Valencia, Spain \\ ${ }^{5}$ Department of Systems Analysis, Integrated Assessment and Modeling, Swiss Federal Institute for Aquatic Science and \\ Technology, Ueberlandstrasse, 133, 8600 Duebendorf, Switzerland \\ ${ }^{6}$ Department of Environmental Science, University of Basel, Petersplatz 1, 4003, Basel, Switzerland
}

Correspondence to: T. P. Karjalainen (timo.p.karjalainen@oulu.fi), P. M. Rossi (pekka.rossi@oulu.fi), P. Ala-aho (pertti.ala-aho@oulu.fi), R. Eskelinen (reskeline@paju.oulu.fi), K. Reinikainen (kalle.reinikainen@poyry.com), B. Kløve (bjorn.klove@ oulu.fi), M. Pulido-Velazquez (mapuve@hma.upv.es), and H. Yang (hong.yang@eawag.ch)

Received: 20 June 2013 - Published in Hydrol. Earth Syst. Sci. Discuss.: 5 July 2013

Revised: 15 November 2013 - Accepted: 20 November 2013 - Published: 18 December 2013

\begin{abstract}
Multi-criteria decision analysis (MCDA) methods are increasingly used to facilitate both rigorous analysis and stakeholder involvement in natural and water resource planning. Decision-making in that context is often complex and multi-faceted with numerous trade-offs between social, environmental and economic impacts. However, practical applications of decision-support methods are often too technically oriented and hard to use, understand or interpret for all participants. The learning of participants in these processes is seldom examined, even though successful deliberation depends on learning. This paper analyzes the potential of an interactive MCDA framework, the decision analysis interview (DAI) approach, for facilitating stakeholder involvement and learning in groundwater management. It evaluates the results of the MCDA process in assessing land-use management alternatives in a Finnish esker aquifer area where conflicting land uses affect the groundwater body and dependent ecosystems. In the assessment process, emphasis was placed on the interactive role of the MCDA tool in facilitating stakeholder participation and learning. The results confirmed that the structured decision analysis framework can foster learning and collaboration in a process where disputes and diverse
\end{abstract}

interests are represented. Computer-aided interviews helped the participants to see how their preferences affected the desirability and ranking of alternatives. During the process, the participants' knowledge and preferences evolved as they assessed their initial knowledge with the help of fresh scientific information. The decision analysis process led to the opening of a dialogue, showing the overall picture of the problem context and the critical issues for the further process.

\section{Introduction}

Groundwater resources are facing increasing pressure from land use and water abstraction. There is evidence of dramatic changes in aquifer water resources (Wada et al., 2010). However, public awareness of groundwater resources, groundwater dependent ecosystems (GDEs) and problems related to the pollution and decline of groundwater levels is still surprisingly poor (Kløve et al., 2011a, b).

Due to the high degree of complexity and uncertainty in groundwater management, a combination of thorough analysis and informed deliberation is clearly useful and important 
for policy formulation. Generally, the need for interdisciplinary and participatory processes combining scientific and local knowledge in environmental research and planning is widely acknowledged in environmental, natural resource and water governance (e.g., Renn, 2006; Silva et al., 2010; PahlWostl et al., 2010).

Multi-criteria decision analysis (MCDA) has increasingly been used as a methodology for fusing available scientific and technical information with stakeholder knowledge and values to support decisions in many fields, including natural resources and environment management (Belton and Stewart, 2002). There is a wide range of MCDA applications covering different fields of natural resource management and environmental planning (for references and earlier reviews see, e.g., Keefer et al., 2004; Kiker et al., 2005; Hajkowicz and Collins, 2007; Kangas et al., 2008; Huang et al., 2011). MCDA is increasingly used to support stakeholder participation in environmental and natural resource planning, and experiences from many participatory MCDA applications have been positive (e.g., Pykäläinen et al., 1999; Qureshi and Harrison, 2001; Regan et al., 2007; Hajkowicz and Collins, 2007; Munda, 2008; Marttunen and Hämäläinen, 2008; Marttunen et al., 2013). There is also a fairly rich body of literature related to the use of multi-criteria analysis (MCA) or MCDA in participatory water resource management projects (Brown et al., 2001; Hostmann et al., 2005a, b; Messner et al., 2006; Hajkowicz and Collins, 2007; Salgado et al., 2009; Calizaya et al., 2010; Silva et al., 2010; Weng et al., 2010; Straton et al., 2011; Coelho et al., 2012; Reichert et al., 2013).

Multi-criteria methods have often been applied to the analysis of groundwater management, mostly in the form of multi-objective optimization (e.g., Willis and Liu, 1984; Yazicigil, 1990; Duckstein et al., 1994; Yang et al., 2001; Almasri and Kaluarachchi, 2005). With a few exceptions (e.g., McPhee and Yeh, 2004), most of the decision analysis so far has been restricted to the assessment of tradeoffs among the selected objectives and to the determination of nondominated solutions (Pareto set), and the approaches have not been interactive or participatory (as they have omitted the explicit inference of the stakeholders' preferences).

In the decision analysis literature, there is hardly any discussion of whether people have really understood the method applied and its assumptions - in many cases such problems have remained unnoticed (Hämäläinen, 2004). It seems that behavioral questions - such as how well the deliberative process is understood, how thoughtfully input is provided, and how meaningfully outputs are considered - are still without clear answers both in theoretical and practical areas. We need more research on methods that could facilitate the participants' understanding of a problem and enable them to make sense of the evaluative task assigned to them.

The use of MCDA in a participatory way is a challenging task requiring careful design and expertise related to the methodology and process (Sparrevik et al., 2011).
Many problems have been identified, including the need for transparent and easily applied methods for engaging stakeholders and for developing a robust decision model that accounts for the time and resource constraints experienced by practitioners attempting real-life MCDA applications (Huang et al., 2011). It is said that successful deliberation as part of the decision analysis approach depends on learning, "which in turn depends on the ability of those leading the process to create an environment that fosters dialogue, questioning, and self-reflection" (Gregory et al., 2012, p. 246). This behavioral and learning viewpoint is important when applying any decision analysis framework. The process should be planned in a way that all of the participants can fully understand the reasoning and results. However, practical applications of decision-support methods are often too technically oriented and hard to use, understand or interpret (Kangas et al., 2008). The learning aspect has been mentioned in many papers on MCDA (e.g., Kangas et al., 2001) but not systematically studied in practice.

This paper analyzes the potential of interactive MCDA especially the decision analysis interview (DAI) approach (Marttunen and Hämäläinen, 2008) - for facilitating stakeholder involvement and learning in groundwater management. It evaluates the results of an MCDA process conducted for the Rokua esker aquifer in northern Finland. The disturbance of the system's water dynamics by human activity is leading to the loss of ecosystem goods and services, affecting recreation and other associated activities in the area. The MCDA started a process, in association with stakeholder groups, to find out ecologically sound, economically feasible and socially acceptable options for sustainable land-use management of the esker area and to evaluate these alternatives systematically and transparently.

We would like to mention that there are other approaches (e.g., cooperative discourse, Renn, 2004; deliberative mapping, Burgess et al., 2007) other than the presented MCDA/DAI approach that can also foster learning and promote stakeholder involvement. We have applied the DAI approach, because we want to specifically assess whether there is any improved understanding of the groundwater issue in the Rokua area among the participants after the MCDA process, and if there is, how the applied approach enhanced the conditions for learning. The questions to be answered include: did the process facilitate stakeholder involvement and learning among the participants? What was the benefit of the interactive MCDA process for the land-use planning in the area? Was the process successful in enhancing the conditions for learning (meaningful participation and dialogue among participating stakeholders) and in fostering learning (especially a common understanding of the problem)? 


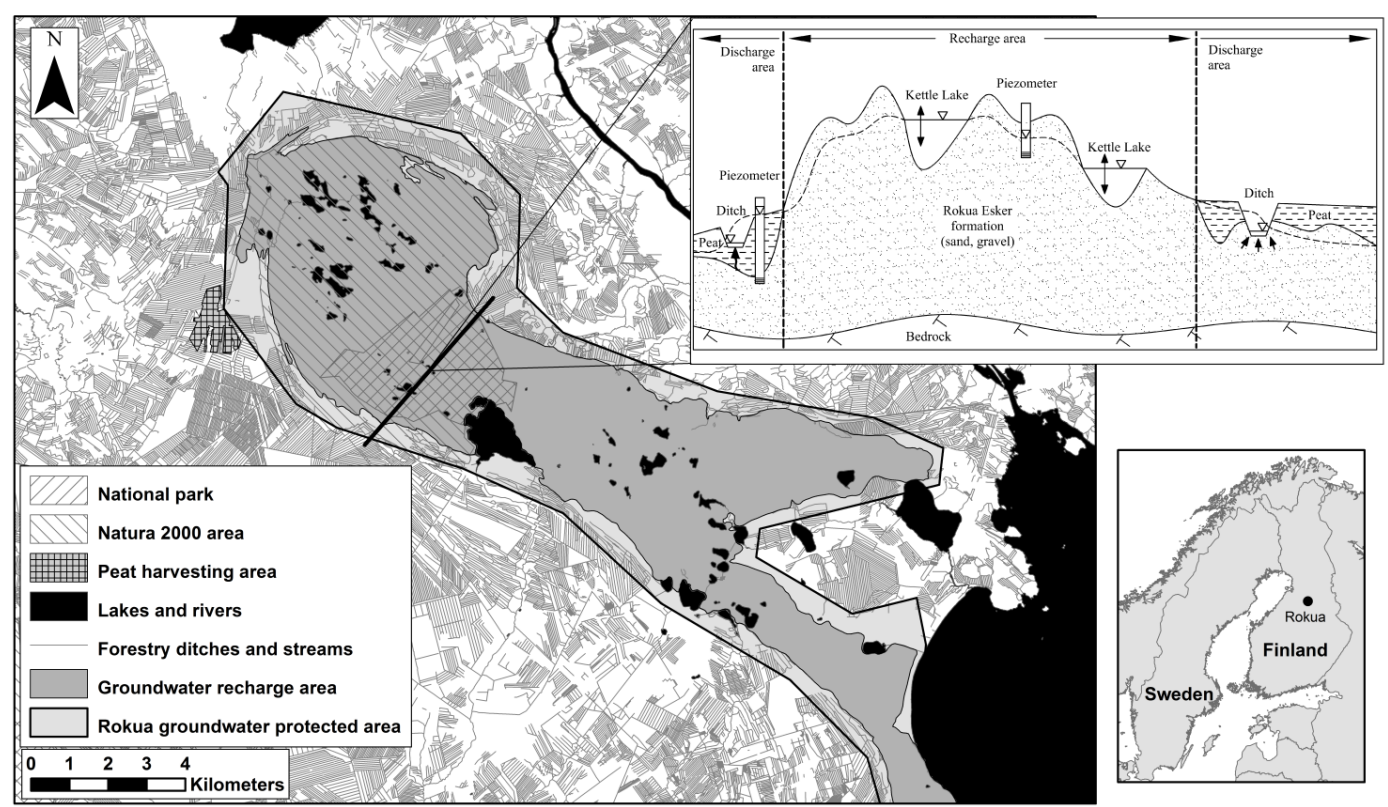

Fig. 1. The Rokua esker area and a cross-section sketch of the esker with recharge and discharge areas.

\section{The case study: land use in the Rokua esker area in Finland}

The Rokua esker aquifer is one of the largest groundwater bodies in Finland with an area of $139 \mathrm{~km}^{2}$, of which $92 \mathrm{~km}^{2}$ is groundwater recharge area (Fig. 1). Aquifer thickness varies from 30 to $100 \mathrm{~m}$ and consists of sand and local deposits of gravel. The esker is protected under the European Union's Natura 2000 network and contains a national park. The Rokua esker aquifer is an example of unique dune formations caused by the wind and fluvial and coastal currents as well as deep depressions and kettle lakes formed by the preferential melting of ice. Among the area's key ecosystems are the crystal clear, oligotrophic, groundwaterdependent kettle lakes. Recently, Rokua was also introduced as a member of the UNESCO Geoparks Network. It is a popular recreation area and holiday resort with hotels and second homes. The economic impact of the annual 120000 tourists (mainly hikers and cross-country skiers) on the local economy is significant (Jurvakainen, 2007).

As in most inland eskers in Finland, the Rokua groundwater system is unconfined in the recharge zone. It discharges into peatlands, where peat confines the groundwater. These peatlands have been used for forestry, peat extraction and, on a smaller scale, agriculture. In the past, Finnish water management did not consider drainage in the groundwater discharge zone as a threat to the esker aquifer. Drainage for forestry was supported by government subsidies and conducted on a large scale from the 1950s to 1980s. Possible environmental impacts of this practice were studied and noticed only later (e.g., Kløve et al., 2011a). Currently, drainage of pristine peatlands is rare, but poorly functioning drainage systems are enhanced by drainage improvements (i.e. the reopening of filled ditches).

At Rokua, groundwater-dependent lake levels were observed to decline after a drought period in the 1980s, and the same decline was also repeated after later dry seasons. The need for research in the Rokua area was catalyzed by a dry period in the 2000s, when the water level of the Rokua lakes and groundwater were, as in the 1980s, again substantially declining. At this point, the decline was attributed to several factors, including forestry ditches and the nearby peat harvesting area. Intensive hydrogeological studies of the Rokua groundwater system started in 2008. Thus far, the studies have shown that the groundwater level and the dependent lake levels are closely related to annual changes in precipitation and evapotranspiration. After a dry period, the groundwater levels declined for several years, whereas high precipitation periods again gradually raised the water levels. However, studies have also suggested a slower, longer-term decline in the Rokua water levels. This decline could not be explained by climate conditions, as effective precipitation (precipitation-evapotranspiration) has increased during the $30 \mathrm{yr}$ reference period from 1980 to 2010.

According to a study by Rossi et al. (2012) and the first tentative groundwater flow model, the anticlinal Rokua esker groundwater discharge zone conditions are dependent on land use. Therefore, drainage (either for forestry, peat extraction or agriculture) of peatland is likely to be one of the reasons for the long-term decline of the Rokua groundwater level. As the study results are still uncertain concerning how much the discharge zone conditions actually affect the esker groundwater level, precautionary principles should be 
applied in the Rokua area until more exact scientific evidence becomes available.

The EU Groundwater Directive states that the quantitative and qualitative deterioration of groundwater should be prevented. However, public awareness of the problems relating to the decline in groundwater level is in many cases poor among the EU member states (Kløve et al., 2011a, b). The same problem concerns the Rokua esker area, as public knowledge of groundwater is limited. In Rokua, groundwater is the connecting factor between the surface waters, i.e. the esker lakes and the streams and ditches within the peatland discharge area. Accusations among various stakeholders concerning the reasons for the water level decline during the 2000s have increased tensions between the different stakeholder groups in the area. To open discussions between the stakeholders on the role of different land uses and their impacts on the Rokua water levels, up-to-date knowledge on groundwater should be distributed. For this reason, the decision analysis tool used in this study was also simultaneously used as a learning tool.

\section{Methodology}

\subsection{The role of MCDA in stakeholder participation and learning}

Increased attention has been paid to the importance of learning in supporting collaborative environmental and natural resource management (e.g., Pahl-Wostl et al., 2010). However, there are multiple, contradictory and confusing definitions of learning. For example, social learning is becoming a normative goal in natural resource management, even though as a concept it has a number of definitions and it is often confused with the conditions necessary to facilitate social learning, such as stakeholder participation (Armitage et al., 2009). Furthermore, the difference between individual and social learning is rarely made (Reed et al., 2010).

Despite a rapidly growing body of literature on learning, especially social learning, there is limited empirical evidence on the role or effectiveness of learning in participatory planning and decision-making. In research, the effects of individual variables on learning are seldom evaluated, and it is seldom tested which techniques can best lead to learning. The evidence on the effectiveness of learning is explored and reported on the basis of hindsight, personal experiences or uses of empirical data extrapolated from activities meant to evaluate other processes or concepts (e.g., participation) (Rodela et al., 2012; Reed et al., 2010)

A collaborative process can facilitate a learning process in which all involved parties, including project managers, scientists and experts, learn from each other. It has been reported that in many cases stakeholder or public participation does not foster learning (e.g., participation is not useful in clarifying the issue) nor lead to better decisions (Booth and Halseth, 2011). However, structured decision-making approaches have been found to help the participants to learn about the options and trade-offs as well as their own and the other participants' values and interests (Gregory et al., 2012).

It has been observed that analytic-deliberative methods can help in conflict mediation when the link between deliberation and structuring or analytical tools is well planned. Rauschmayer and Wittmer (2006) conclude in their evaluation of deliberative and analytical methods that the deficiencies of more traditional decision-aiding tools (which are too complicated and expert-oriented) can be overcome by a combination of multi-criteria and participatory instruments. It seems that the balance between being deliberative and analytical can be achieved well by using interactive MCDA methods. In this way, the approach can be structured and transparent while not being too complex in order to enhance stakeholder participation and learning. However, much more research on different decision analysis methods and learning aspects should be carried out before generalizations can be made.

\subsection{Interactive MCDA in the Rokua case}

The MCDA method applied in the Rokua case is based on the multi-attribute value theory (MAVT) (Keeney and Raiffa, 1976), and it takes advantage of the decision analysis interview (DAI) approach (Marttunen and Hämäläinen, 2008; Marttunen, 2011; Marttunen et al., 2013) based on personal interviews using a multi-criteria model. At the core of the DAI framework is an MCDA-based interactive and individual analysis. In the DAI approach, the entire MCDA process is realized in close co-operation with the key stakeholders. In the interviews, the decision analyst uses MCDA software and poses questions to the interviewee, ensuring that the interviewee's views are taken into account as closely as possible.

In MAVT, a decision problem is formulated with multiple attributes, and these attributes are used in the evaluation of the alternatives. MAVT has been proven to be a systematic and transparent way to model problems with multiple criteria and alternatives when working with stakeholders (see, e.g., Mustajoki et al., 2011). In the interviewing process, the stakeholders or decision-makers are asked to give numerical preference statements which are used to calculate the attribute weights describing the trade-offs between the attributes in the additive value function model. The model derives overall values for the options to represent the stakeholder's overall preference over the options under the condition that the attributes are mutually preferentially independent (see, e.g., Keeney and Raiffa, 1976). In eliciting the weights of the criteria, the interviewees are encouraged to profoundly consider their own values and the trade-offs. This "learning by analyzing" technique is one of the main advantages of the DAI approach (Marttunen and Hämäläinen, 2008). 


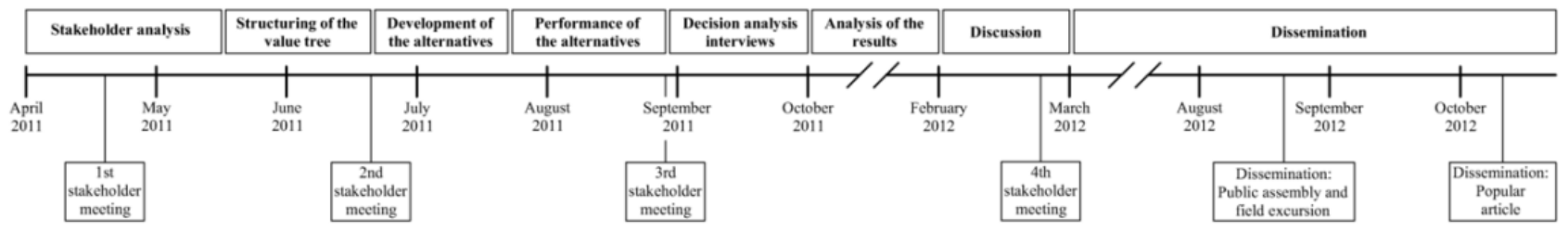

Fig. 2. Decision analysis process in the Rokua case.

In the DAI approach, special attention is paid to the clarity of the process, the choice of tools and capacity building of the participants. The DAI approach has been observed to help the participants in assigning consistent and unbiased weights. In an interactive interview, the analyst can notice possible inconsistencies, misunderstandings and biases in the interviewee's answers (Marttunen and Hämäläinen, 2008; Marttunen et al., 2013). For example, in watercourse planning, the MCDA models have inspired learning and understanding in a different manner than traditional meetings. The interactive use of the models has supported the systematic analysis of the stakeholders' preferences and helped to analyze how the preferences have affected the ranking of the alternatives (Marttunen and Suomalainen, 2005; Marttunen et al., 2013).

Most of the strengths of the MCDA/DAI approach identified are related to a high level of interaction (Marttunen et al., 2013). It is essential for making deliberative judgments that the participants have sufficient understanding of the impact of the different options and the calculation principles of the MCDA model (Anderson and Clemens, 2013). Enhanced learning among stakeholders is clearly connected to building trust and creating commitment to the planning case.

The approach enables more careful answers from interviewees due to the presence of the analyst. When immediate feedback is enabled, possible misunderstandings, mistakes and biases can be detected more accurately than in the compared approaches with less interaction (Marttunen et al., 2013). However, this also means that the decision analyst can unintentionally influence the interviewees' answers and that he/she should be aware of that.

The close interaction with stakeholders also means that the approach requires time and commitment from the stakeholders, making it quite a laborious procedure. In some cases such an intensive interaction can be hard to implement, and trade-offs have to be made between the amount of resources and the effectiveness of MCDA. Depending on the case, interactive MCDA can be realized effectively by using group meetings, for example, Facilitated Work Groups (Phillips and Phillips, 1993), where preference information is gathered and analyzed in a workshop led by the decision analyst. Compared to the DAI approach, there are a fair number of challenges related to group meetings which can hinder stakeholder learning: some participants may have problems following the facilitators guidance in the workshop and
Table 1. List of stakeholder groups and representatives in the decision analysis interviews.

\begin{tabular}{llc}
\hline Stakeholder & Representation & $\begin{array}{c}\text { Number of } \\
\text { interviewees }\end{array}$ \\
\hline Forestry & $\begin{array}{l}\text { Forest Centre (state } \\
\text { organisation) } \\
\text { Forestry association }\end{array}$ & 2 \\
& Forest owner & 1 \\
Regional administration & Groundwater management & 3 \\
& Habitat conservation & 2 \\
Nature park & Forest park services & 1 \\
administration & Chief engineers & 2 \\
Municipalities & Hotel manager & 1 \\
Tourism & Rokua association & 1 \\
Local NGO & Association of owners & 1 \\
Second house owners & Humanpolis/Geopark & 1 \\
Development & & \\
organization & Turveruukki company & 1 \\
Peat production & & \\
\hline
\end{tabular}

understanding the methods and questions correctly. In addition, it is easier to identify biases in preference elicitation in a face-to-face interview than in a workshop for 7 to 20 participants (Marttunen et al., 2013).

\subsection{Application}

The decision analysis process was led by an expert group consisting of researchers from the University of Oulu. The expert group organized altogether four different meetings or workshops with the stakeholders (see Table 1) where the MCDA work was processed. Figure 2 describes the main phases of the decision analysis process.

\subsubsection{Stakeholder analysis and forming of the value tree}

In the first stakeholder meeting, the initial list of stakeholders and the definition of the decision context in the Rokua esker area and groundwater management were presented to the various interest group representatives. As a result of that meeting, a list of stakeholders (see Table 1) to be involved was finalized, and a first draft of the value tree including the stakeholders' objectives concerning groundwater management and land use in the Rokua esker area was formed (see Fig. 3). The next step was to finalize the value tree. 
Table 2. Objectives, attributes and impact matrix of the different alternatives.

\begin{tabular}{|c|c|c|c|c|}
\hline Objective & Attribute(s) & $\begin{array}{l}\text { Business- } \\
\text { as-usual }\end{array}$ & $\begin{array}{l}\text { GW-area } \\
\text { expansion }\end{array}$ & $\begin{array}{l}\text { Active } \\
\text { restoration }\end{array}$ \\
\hline $\begin{array}{l}\text { Normal level of } \\
\text { groundwater and } \\
\text { dependent lakes }\end{array}$ & $\begin{array}{l}\text { Change of average Rokua } \\
\text { water level in } 30 \mathrm{yr} \\
\text { (groundwater and lakes) }\end{array}$ & $-1 \mathrm{~m}$ & $-1-0 \mathrm{~m}$ & $+1 \mathrm{~m}$ \\
\hline $\begin{array}{l}\text { Good ecological } \\
\text { status of lakes } \\
\text { and springs }\end{array}$ & $\begin{array}{l}\text { Chemical state of lakes } \\
\text { Chemical/ecological state of } \\
\text { springs }\end{array}$ & $\begin{array}{l}0 \\
0\end{array}$ & $\begin{array}{l}0 /+ \\
0 /+\end{array}$ & $\begin{array}{l}+ \\
++\end{array}$ \\
\hline $\begin{array}{l}\text { Good } \\
\text { recreational } \\
\text { value of } \\
\text { second homes }\end{array}$ & $\begin{array}{l}\text { Recreational value change } \\
\text { of second homes at kettle } \\
\text { lakes in } 30 \mathrm{yr}\end{array}$ & $\begin{array}{l}-150000- \\
-230000 €\end{array}$ & $\begin{array}{l}0- \\
-230000 €\end{array}$ & 0 \\
\hline $\begin{array}{l}\text { Attractive tourist } \\
\text { resort }\end{array}$ & $\begin{array}{l}\text { Change in attractiveness of } \\
\text { Rokua for tourists in } \\
30 \mathrm{yr}\end{array}$ & - & 0 & + \\
\hline $\begin{array}{l}\text { Profitable } \\
\text { forestry }\end{array}$ & $\begin{array}{l}\text { Forestry income loss in } \\
30 \mathrm{yr} \text { compared to } \\
\text { current state }\end{array}$ & 0 & $\begin{array}{l}-50000- \\
-250000 €\end{array}$ & $\begin{array}{l}-500000- \\
-2500000 €\end{array}$ \\
\hline $\begin{array}{l}\text { Minimal loss for } \\
\text { peat production }\end{array}$ & $\begin{array}{l}\text { Income loss for peat } \\
\text { production or losses caused } \\
\text { by restoration of peat } \\
\text { harvesting area }\end{array}$ & 0 & $0 /-$ & - \\
\hline
\end{tabular}

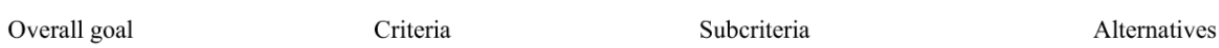

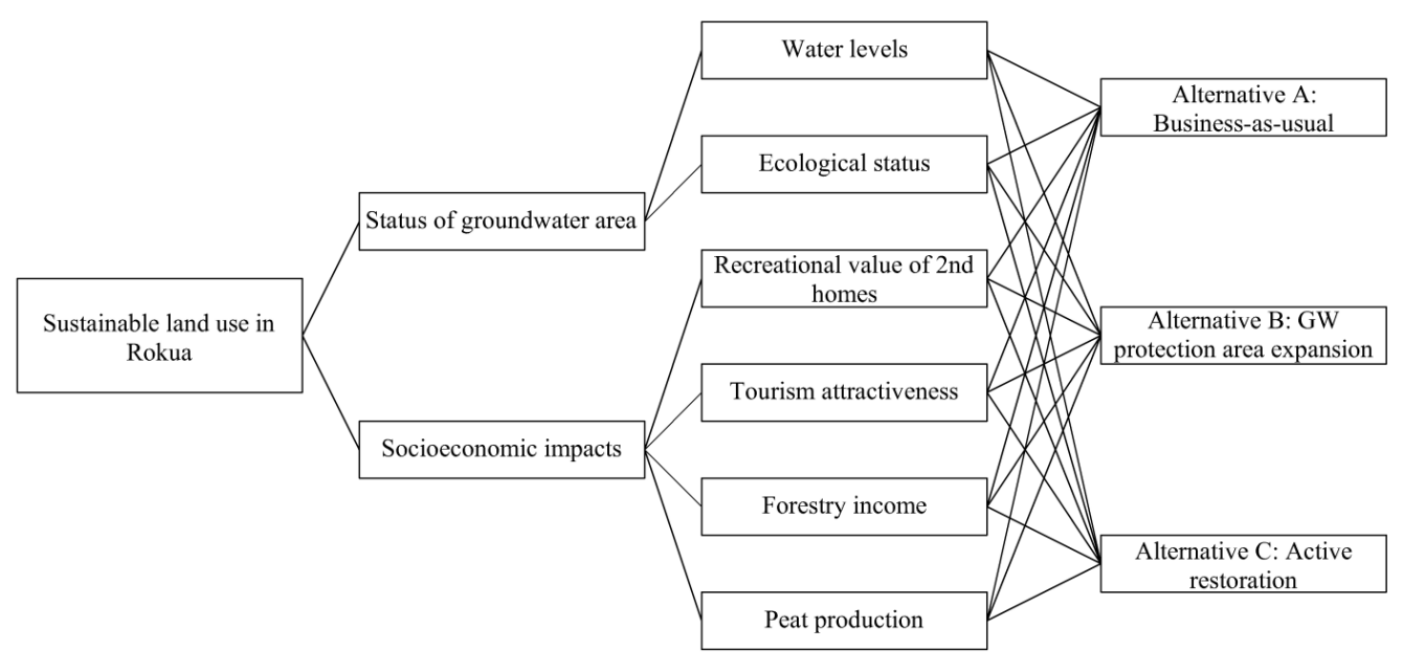

Fig. 3. Value tree for the multi-criteria decision analysis in Rokua.

In the second stakeholder meeting, the objectives (reflecting "what matters" to those whose views should be considered in a given decision context) were discussed on the basis of the initial proposal for the value tree. In the same meeting, the attributes for the measurement of each objective were set up (Table 2).
The meeting mainly focused on the discussion of the objectives and their measurement. For example, there was discussion about how to measure the change in tourism if the water levels in the kettle lakes continue to decrease. It was generally accepted that changes in the number of tourists visiting the area due to water level variations cannot be 

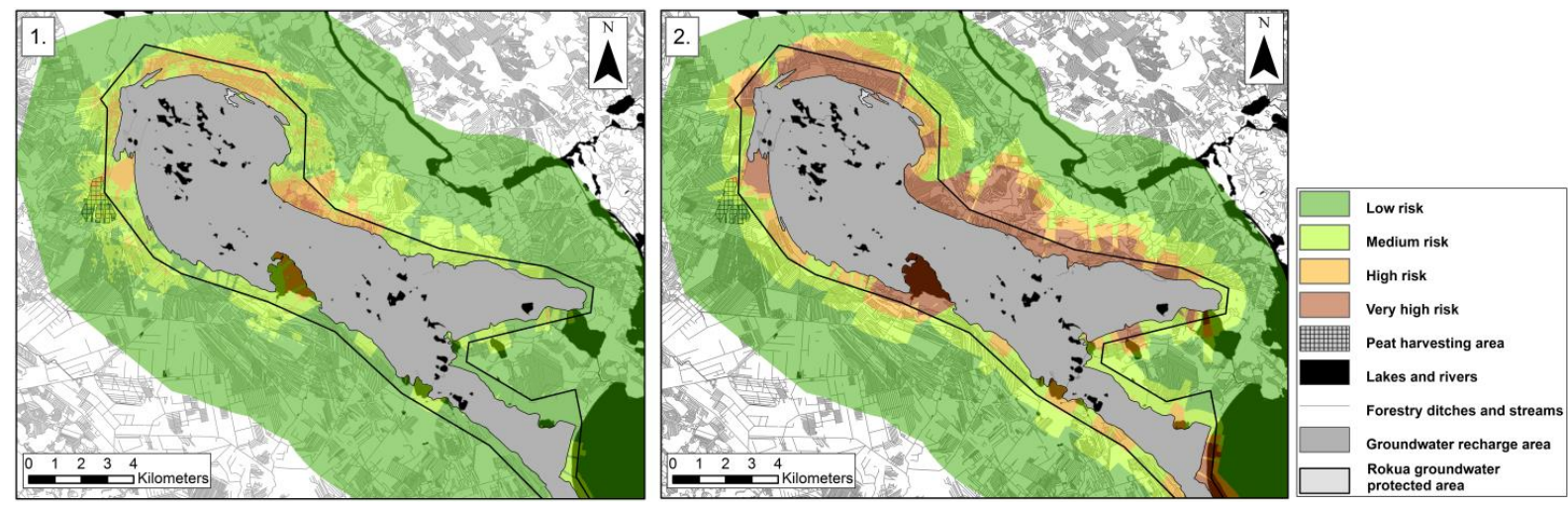

Fig. 4. Groundwater exfiltration risk analysis maps for Rokua with different data sets. In Map 1, risk analysis was based on terrain slope, distance from the recharge zone and springs, and peat thickness. In Map 2, peat thickness was not considered.

evaluated convincingly, since many other issues (e.g., the overall standard of tourism services) influence the attractiveness of the area in the future. The ecosystem services of the kettle lakes that provide recreational and aesthetic benefits for visitors are one of the area's attractions, but they do not form the only and decisive factor for the whole tourism sector. Indirect economic benefits of tourism and forestry for the local and regional economy were also discussed. It was decided not to focus on these benefits in the assessment due to the considerable level of uncertainty concerning how much water level changes may affect these factors.

In this study, a linear additive value function model has been applied for the weighted aggregation of the single attribute values, which is the simplest and most used aggregation model in MAVT (Belton and Steward, 2002). Keeney and Raiffa (1976) provide conditions under which the linear additive model can be used. This model is commonly applied without explicitly testing, e.g., the preferential independence of the attributes. We did not test this either in this case, but we consider that the preferential independence of the attributes holds into the 6 selected attributes: the 2 attributes related to the groundwater status (quantitative, chemical), and the 4 attributes related to economic values (second home, tourism, forestry, peat production losses).

\subsubsection{Development of alternatives and impact assessment}

The possible land-use management options were considered while structuring the value tree. The set of alternatives was first formed by the expert group and revised in the second stakeholder meeting. The alternatives developed reflect the key objectives, interests and issues of conflict.

\section{Alternative A: business-as-usual}

Forestry practices continue as usual; reopening of drainage ditches in the groundwater area is not prohibited but is under case-by-case consideration by the regulators.

\section{Alternative B: expansion of the groundwater protected area}

Three- to five-square-kilometer expansion of the Rokua groundwater protected area into the surrounding peatlands where groundwater is confined under peat (exfiltration risk areas, Fig. 4). Forestry practices will be limited or forbidden in these areas. The environmental administration's control over the area will be strengthened.

\section{Alternative C: active restoration (technical solutions) of peatlands}

Restoration of critical groundwater exfiltration areas either by damming or filling the drainage ditches. This alternative focuses on adaptive management efforts to locate the most critical areas of groundwater exfiltration instead of protecting larger land areas.

Locations and areas for groundwater area expansion (Alternative B) and restoration targets (Alternative C) were estimated by using the groundwater exfiltration risk prediction method developed for Rokua by Eskelinen (2011). The method estimated the most likely locations for groundwater exfiltration from the slope of the esker, distance from the recharge zone, distance from springs, baseflow of the discharge area watersheds and peat thickness (Fig. 4).

The impact assessment of the selected alternatives was conducted by the expert group after the second stakeholder meeting. The hydrological, ecological and socioeconomic impacts of the proposed alternatives during a $30 \mathrm{yr}$ period are presented in Table 2. The impact assessment is based on the conducted studies and the preliminary results of ongoing research in the area. As the assessment is partially based on preliminary results and the time span of the assessment is $30 \mathrm{yr}$, the uncertainty of the impact assessment is considered to be relatively high. For this reason, some of the impacts are studied using less precise, qualitative measures. These qualitative measures indicate if the alternative has a 
negative impact $(-)$, if there is no change from the current situation ( 0$)$, or if there is a positive $(+)$ or highly positive impact $(++)$. For example, active restoration is assessed to have a highly positive impact on the springs surrounding Rokua. A more exact evaluation of the impacts to the attributes is presented in the Supplement.

\subsubsection{Decision analysis interviews}

Stakeholder preferences were taken into account in the MCDA model by means of decision analysis interviews. In the third stakeholder meeting and learning workshop with the interviewees, the results of the impact assessment were presented and the decision analysis process was described. A questionnaire for the interview and an information package were handed out to the interviewees with information about the case, the approach and the interview process. The package also included a description of the applied value tree, the grounds for the alternatives, criteria and measurement value estimates.

The interviews, conducted by two researchers in September 2011, involved 19 representatives of the stakeholder groups (see Table 1). In one case, three interviewees (representing the same stakeholder group and organization) wanted to give mutual criteria weights, so finally 17 different weighting profiles and evaluations were gathered in order to infer the preferences of the main stakeholder groups (see Supplement: preference elicitation in the decision analysis interviews). We used local scales as attribute measurement values on a $0-1$ value scale. Thus, for each criterion, the lowest attribute value among our set of alternatives was mapped to 0 and the highest value to 1 (Belton and Stewart, 2002).

We selected the SWING method for eliciting the weights for the criteria (von Winterfeldt and Edwards, 1986). The SWING procedure was chosen in order to ensure that the participants account for the decision context by first identifying the most important attribute, and then the relative importance of the other attributes was compared to it. It is crucial when eliciting weights for the highest level attributes that the participant is fully aware of the meaning of the attributes. Therefore, a bottom-up approach was applied in which the weights were first elicited to the attributes on the lowest level.

The interviews lasted from one and a half to four and a half hours. In the first half of the interview, we laid out the general principles of the DAI approach, the case and the applied model in order to make sure that the interviewee had understood all of the details relating to the interview process. After this, the interviewee's preferences were fed into the model using the Web-HIPRE software (Mustajoki and Hämäläinen, 2000). The final phase of the interview consisted of analyzing the results and explaining the reasons behind them to the interviewee.

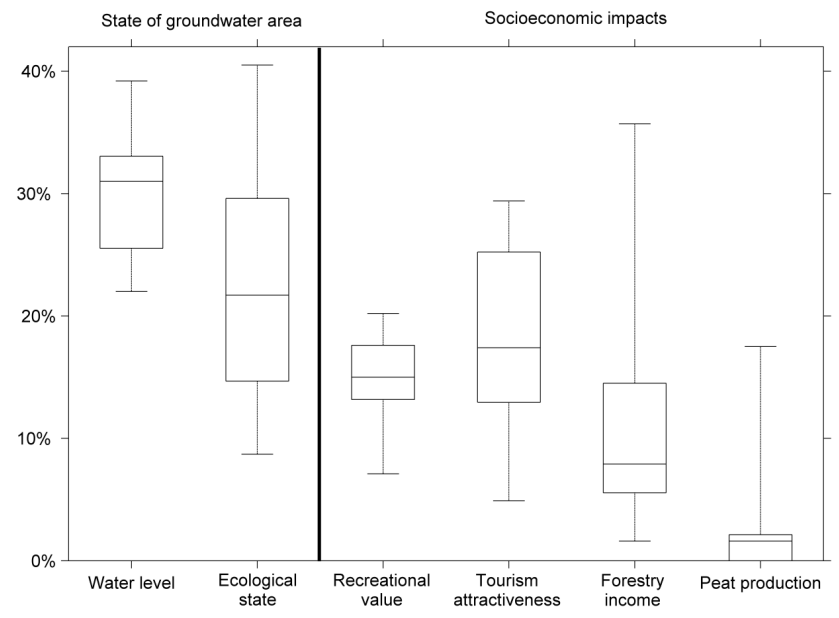

Fig. 5. Importance weights of the criteria in the Rokua groundwater case given by the interviewed stakeholders (min, median, 75th percentile, max).

\subsection{Data for the evaluation}

The data for the evaluation comprises mainly the results of the decision analysis interviews and the feedback survey for the participating stakeholders. The feedback questionnaire was introduced in the fourth stakeholder meeting, where the results of the MCDA process and interviews were presented and discussed. The participants were asked, for example, to evaluate the suitability of the applied MCDA approach for meeting the different objectives and the success of the implementation of MCDA in Rokua in supporting learning (see Fig. 8).

\section{Results and evaluation}

\subsection{Results of the decision analysis interviews}

\subsubsection{Importance of objectives}

The interviewees were asked to consider the range of impacts of the alternatives and the importance of the objectives/issues considered. As the results show (Fig. 5), there is agreement among stakeholders that the water level of the lakes and the aquifer (more than $30 \%$ share of the total weight - median value) is the most important criterion in the context of the Rokua case study. Most of the interviewees considered this criterion as the basic unit when measuring the success of land-use management.

The ecological status of lakes and springs receives a more than $20 \%$ share of the total weight (median value, Fig. 5), but there is much more disagreement (range between $\mathrm{min} / \mathrm{max}$ and 75th percentile) about how important this criterion is and about the impact that the proposed alternatives might cause. The recreational value of second homes was considered an important objective, but the impacts (measured by 
change of monetary value per second house) were rated low by the participating stakeholders. Therefore, the overall importance of this criterion (median value of weights) is set as being smaller than that of the water level, ecological status and tourism attractiveness.

Tourism attractiveness was seen as a significant issue for the Rokua area and its surrounding municipalities. However, some interviewees estimated that the marketing and development of new tourism services is more decisive for the attractiveness of the area than the state of the water bodies or lake water levels. The importance of forestry to the local economy was generally recognized among the interviewees, but the impact of the alternatives on forestry income was considered peripheral. Here the forestry representatives disagreed, emphasizing (more than others) the indirect incomes and monetary flows to the regional and national economy. Peat production was considered to be the least important criterion. There are two reasons for that: first, risk analysis and hydrological studies showed that the role of peat production in the waterlevel decline in the Rokua esker area was minimal. Second, during the MCDA process, the representative from the peat harvesting company announced that peat harvesting in the area would end by 2018 .

\subsubsection{Desirability of alternatives}

The results (Fig. 6) indicate that all stakeholder groups are willing to accept that some measures should be promoted in the esker area in order to improve the hydrological and ecological conditions in the area. The ranking of the alternatives shows that active restoration (Alternative $\mathrm{C}$ ) is the preferred one among all interviewees. However, the differences in the preferences for the alternatives are not substantial among the stakeholders stressing the significance of forestry (left side of Fig. 6) as compared with the stakeholders mainly emphasizing the ecological and hydrological issues (right side of Fig. 6), who clearly prefer Alternative B over A, and C over B.

\subsubsection{Different stakeholders' viewpoints}

The analysis revealed that different views about the impacts of the different alternatives and the importance of the criteria can be found. Three different viewpoints of stakeholders were elicited from the analysis: forestry, administrative and local economy.

The forestry viewpoint focuses its concern on the adverse economic impacts on forestry (Fig. 7). This can be noticed from the high value given to the BAU alternative, where negative impacts on forest income can be avoided. The proponents of this viewpoint also emphasize the indirect impacts of forestry on the local, regional and even national economy.

Both the local economy viewpoint (Fig. 7) and the administrative viewpoint (Fig. 7) give more emphasis to the ecological and hydrological objectives. According to the local

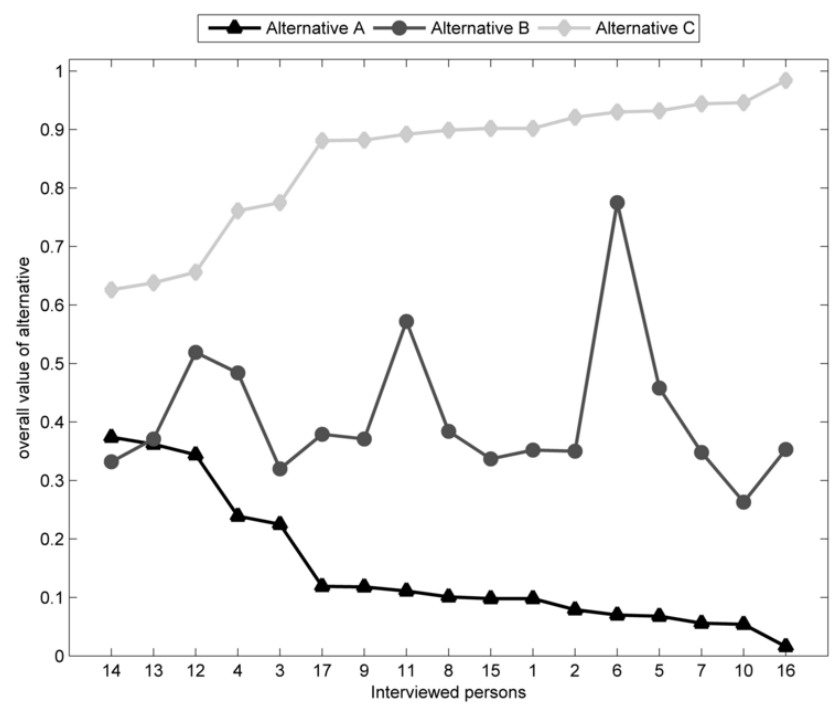

Fig. 6. Overall values of the alternatives for each interviewed stakeholder.

economy viewpoint, the water levels and the ecological status of the water bodies should be kept in a good condition, since tourism is the most important source of local income, jobs and tax revenues. Also, the attractiveness of the area (weighted as the most important criteria) depends on the ecosystem services provided by the specific types of local esker ecosystems.

The administrative perspective (Fig. 7) places more emphasis on the ecological and hydrological criteria than the other two points of view. The overall value of Alternative B is greater among the representatives of this group compared to the other groups. The administrators believe that the positive impacts on the groundwater level and the ecological status of the lakes and springs can also be achieved by expanding the boundaries of the groundwater protected area.

\subsection{Evaluation of the approach by the stakeholders}

At the final workshop, the members of the participating stakeholder groups were asked to evaluate both the suitability of the applied approach for this case and the practical implementation of the process including their understanding of the process and the results. The mean mark for the overall evaluation of the success of the applied approach was 8.3 (on a scale from 4 to 10). The approach was considered by the stakeholders the most suitable for the identification of the key issues of the problem, for increasing the understanding of the views of the different stakeholder groups and for the collection of information (Fig. 8). In the meeting discussions, the stakeholders appreciated the method's capability for collecting information from different sources while at the same time showing the different views of the importance of the different land-use practices and the overall objectives of 

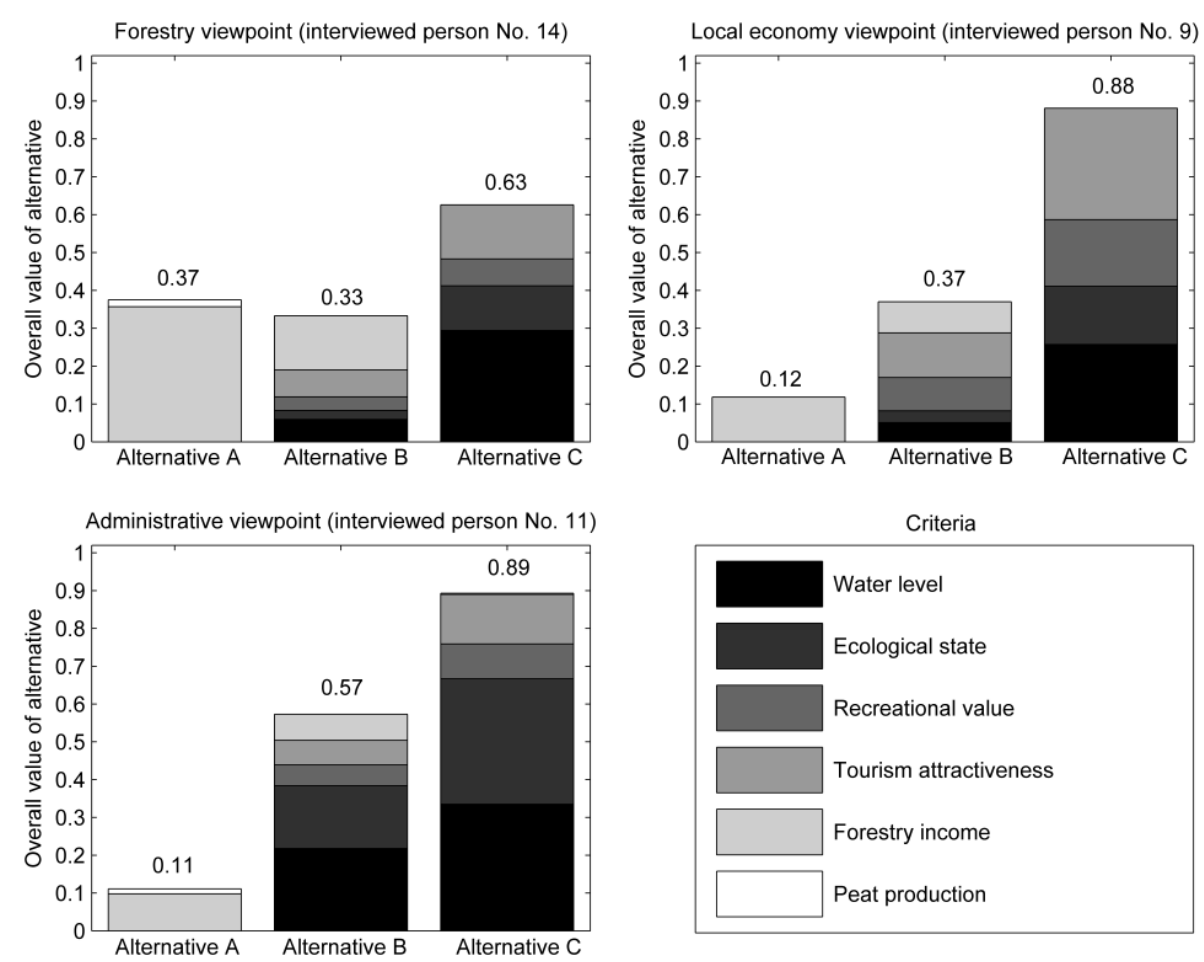

Fig. 7. Overall values of the forestry, local economy and administrative perspectives.

the stakeholders. There was agreement that this was the most significant benefit of the MCDA method.

All participating stakeholders considered the MCDA process necessary as a starting point and as a basis for further negotiation about the land use in the area. Although the results show that the MCDA process as such was not enough to find a solution that is acceptable for all, most of the stakeholder representatives think that the applied MCDA process is highly useful for Rokua's land-use planning (Fig. 8). In their feedback evaluations most of the respondents considered personal learning to have occurred during the process: their understanding of the alternatives, impacts and different views increased. For the analysts, it is obvious that the participating stakeholders learnt about Rokua's groundwater system itself, about how land-use and climate change might affect the system, and about the different stakeholders' preferences. Computer-aided interviews helped the participants to see how their preferences affected the desirability and ranking of the alternatives. Yet, the participants considered weighting as a challenging task and some of them have problems understanding the obtained results.

\section{Findings and conclusion}

The aim of the MCDA process was to support stakeholder participation and increase the overall understanding of the problem for all parties. The focus was on MCDA as an actor system (used in an interactive participatory process), not as an expert system (Kain and Söderberg, 2008). In the beginning of the MCDA process in Rokua, the groundwater management issue seemed to be an "unstructured problem" with no consensus concerning either the goals or the means and with great scientific uncertainty. In this kind of context, decision-making requires a high level of participation by actors holding conflicting perspectives and interests. Policy development becomes a learning process, a dialogue where the actors develop and reflect upon conflicting perspectives (Turnhout et al., 2008).

The MCDA process in the Rokua case was successful in finding a way towards sustainable land use in the esker aquifer area. First, it has opened the discussion about possible land-use management options in a conflicting situation with a considerable amount of distrust between the different stakeholders. Stakeholder meetings, as well as structured and transparent methods of analysis, have enabled the discussion and consideration of other points of view, and especially the reflection on the participants' own preferences in this context.

We have observed that the participants' understanding evolved during the process as they assessed their previous knowledge about new scientific and socioeconomic information and reflected on their preferences in the context of new knowledge and specific options. When the participants had an opportunity to see visually their attribute weights and the effects of these on the desirability of the alternatives, this interactive and iterative way improved the participants' trust 
Suitability of the decision analytical approach for meeting the following objectives

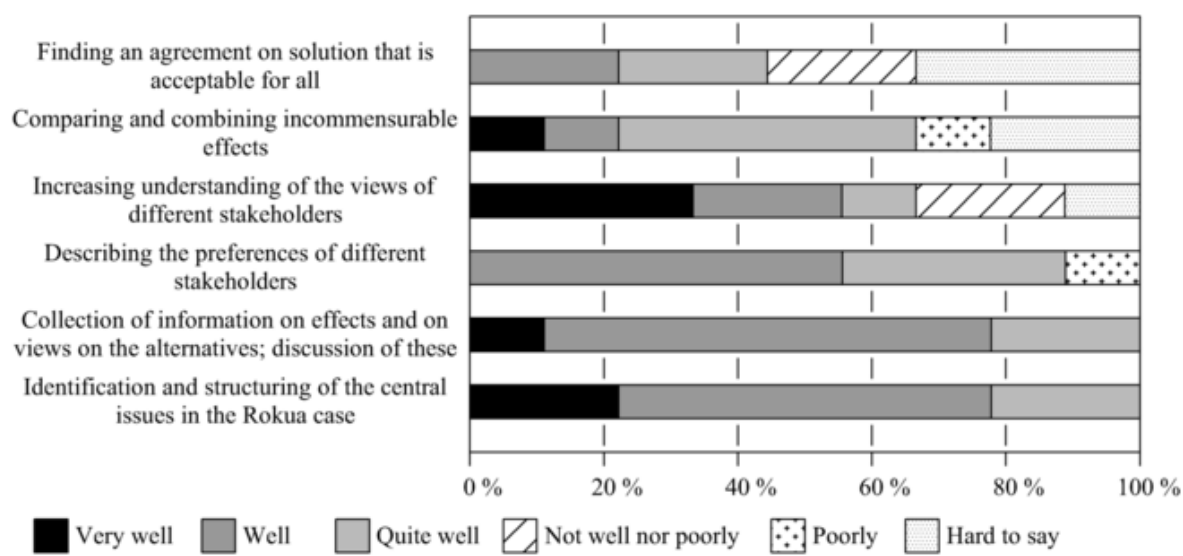

Implementation of the decision analytical approach in practice

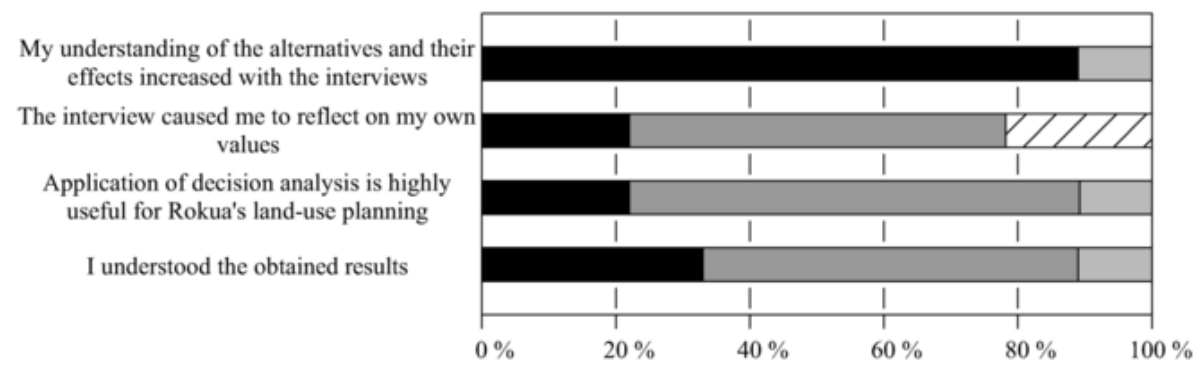

Fully agree $\square$ Partly agree $\square$ No opinion $\square$ Partly disagree $\quad \because$ Fully disagree

Fig. 8. Results of the feedback questionnaire among the participants of the MCDA process.

towards the method and promoted the transparency of the whole process - this has also been observed with earlier DAI studies (Marttunen and Hämäläinen, 2008; Marttunen et al., 2013). In the beginning of the process, the stakeholders' comments and arguments in defense of their prior points of view and the interests of their stakeholder group were observed to be more rigid compared with later stakeholder meetings. The analysis was effective in opening a dialogue.

Second, the MCDA analysis has revealed that the stakeholders actually agree on many crucial issues. The most important issue is that some active measures should be realized in the esker area in order to hinder further decline of the groundwater levels. However, the stakeholders in the Rokua case still disagree with each other about the measures and the effects of the alternatives.

Third, the MCDA process has informed decision-makers about the possible alternatives in land-use management in the Rokua esker area. The MCDA work can be seen as a first step in the process of building up a sustainable land-use plan. It has opened the way towards a new process, showing an overall picture of the problem and decision contexts as well as the different views of the stakeholders (agreements and disagreements), and has identified the critical issues (e.g., new research needed) in furthering the process.

The common purpose of MCDA methods has been to evaluate and choose among alternatives based on multiple criteria using systematic analysis that overcomes the limitations of unstructured individual or group decision-making. However, in many planning processes the ranking of the alternatives may be less important than other process outputs, such as the identification of knowledge gaps, improved and shared understanding about the situation or explication of the diversity of different views. According to our experience with MCDA/DAI approach in the Rokua case (as well as Marttunen et al., 2013; Karjalainen et al., 2013 in other cases), in a highly interactive MCDA process the stakeholders gain a better understanding about the groundwater issue, different viewpoints as well as key uncertainties. While the process may not lead to a specific action plan, it can provide a basis for better cooperation.

\section{Supplementary material related to this article is available online at http://www.hydrol-earth-syst-sci.net/ 17/5141/2013/hess-17-5141-2013-supplement.pdf.}


Acknowledgements. This study was funded by the GENESIS project (contract number 226536) under the EU's 7th Framework Programme and the Academy of Finland (project number 128377). We are grateful to all the stakeholders who participated in the study process and Mika Marttunen to his methodological advices during the study process.

Edited by: G. Characklis

\section{References}

Almasri, M. N. and Kaluarachchi, J. J.: Multi-criteria decision analysis for the optimal management of nitrate contamination of aquifers, J. Environ. Manage., 74, 365-381, 2005.

Anderson, R. M. and Clemens, R.: Toward an improved methodology to construct and reconcile decision analytic preference judgments, Decis. Anal., 10, 121-134, 2013.

Armitage, D., Plummer, R., Fikret, B., Arthur, R. I., Charles, A. T., Davidson-Hunt, I. J., Diduck, A. P., Doubleday, N. C., Johnson, D. S., Marschke, M., McConney, P., Pinkerton, E. W., and Wollenberg, E. K.: Adaptive co-management for social-ecological complexity, Front. Ecol. Environ., 7, 95-102, 2009.

Belton, V. and Stewart, T. J.: Multiple Criteria Decision analysis An Integrated approach, Kluwer Academic publisher, Norwell, Massachusetts, USA, 2002.

Booth, A. and Halseth, G.: Why the public thinks natural resources public participation processes fail: A case study of British Columbia communities, Land Use Policy, 28, 898-906, 2011.

Brown, B., Neil-Adger, W., Tompkins, E., Bacon, P., Shim, D., and Young, K.: Trade-off analysis for marine protected area management, Ecol. Econ., 37, 417-434, 2001.

Burgess, J., Stirling, A., Clark, J., Davies, G., Eames, M., Staley, K., and Williamson, S.: Deliberative mapping: a novel analyticdeliberative methodology to support contested science-policy decisions, Publ. Understand. Sci., 16, 299-322, 2007.

Calizaya, A., Meixner, O., Bengtsson, L., and Berndtsson, R.: Multi-criteria Decision Analysis (MCDA) for Integrated Water Resources Management (IWRM) in the Lake Poopo Basin, Bolivia, Water Resour. Manage., 24, 2267-2289, 2010.

Coelho, A. N., Labadie, J. W., and Fontane, D. L. G.: Multicriteria Decision Support System for Regionalization of Integrated Water Resources Management, Water Resour. Manage., 26, 13251346, 2012.

Duckstein, L., Treichel, W., and Magnouni, S.: Ranking Groundwater Management Alternatives by Multicriterion Analysis, J. Water Resour. Pl. Manage., 120, 546-565, 1994.

Eskelinen, R.: Development and utilization of GIS based groundwater discharge prediction method, master's thesis, University of Oulu, Finland, 78 pp., 2011.

Gregory, R., Failing, L., Harstone, M., Long, G., McDaniels, T., and Ohlson, D.: Structured Decision Making: A Practical Guide to Environmental Management Choices, John Wiley \& Sons Ltd, Chichester, 2012.

Hajkowicz, S. and Collins, K.: A Review of multiple criteria analysis for water resource planning and management, Water Resour. Manage., 21, 1553-1566, 2007.

Hämäläinen, R. P.: Reversing the perspective on the applications of decision analysis, Decis. Anal., 1, 26-31, 2004.
Hostmann, M., Borsuk, M., Reichert, P., and Truffer, B.: Stakeholder values in decision support for river rehabilitation, Arch. Hydrobiol. Suppl., 155, 491-505, 2005a.

Hostmann, M., Bernauer, T., Mosler, H., Reichert, P., and Truffer, B.: Multi-attribute value theory as a framework for conflict resolution in river rehabilitation, J. Multi-Crit. Decis. Anal., 13, 91102, 2005 b.

Huang, I. B., Keisler, J., and Linkov, I.: Multi-criteria decision analysis in environmental sciences: Ten years of applications and trends, Sci. Total Environ., 409, 3578-3594, 2011.

Jurvakainen, A.: Developing tourism from a sustainable developement viewpoint: Regional environmental management system of Rokua, licentiate thesis, University of Oulu, Finland, 2007.

Kain, J.-H. and Söderberg, H.: Management of complex knowledge in planning for sustainable development: The use of multicriteria decision aids, Environ. Impact Assess. Rev., 28, 7-21, 2008.

Kangas, J., Kangas, A., Leskinen, P., and Pykäläinen, J.: MCDM methods in strategic planning of forestry on state-owned lands in Finland: applications and experiences, J. Multi-Crit. Decis. Anal., 10, 257-271, 2001.

Kangas, A., Kangas, J., and Kurttila, M.: Decision support for forest management, Managing Forest Ecosystems, Vol. 16, Springer 2008.

Karjalainen, T. P., Marttunen, M., Sarkki, S., and Rytkönen, A.M.: Integrating ecosystem services into environmental impact assessment: an analytic-deliberative approach, Environ. Impact Assess., 40, 54-64, 2013.

Keefer, D. L., Kirkwood, C. W., and Corner, J. L.: Perspective on decision analysis applications, 1990-2001 (and comments by Cantor, S. B. and Hamalainen, R. P.), Decis. Anal., 1, 4-34, 2004.

Keeney, R. L. and Raiffa, H.: Decisions with multiple objectives: Preferences and value tradeoffs, John Wiley \& Sons, New York, 1976.

Kiker, G. A., Bridges, T. S., Varghese, A., Seager, T. P., and Linkov, I.: Application of multicriteria decision analysis in environmental decision making, Integr. Environ. Assess. Manage., 1, 95-108, 2005.

Kløve, B., Ala-aho, P., Bertrand, G., Boukalova, Z., Ertürk, A., Goldscheider, N., Ilmonen, J., Karakaya, N., Kupfersberger, H., Kvœrner, J., Lundberg, A., Mileusnić, M., Moszczynska, A., Muotka, T., Preda, E., Rossi, P., Siergieiev, D., Šimek, J., Wachniew, P., Angheluta, V., and Widerlund, A.: Groundwater dependent ecosystems, Part I: Hydroecological status and trends, Environ. Sci. Policy, 14, 770-781, 2011a.

Kløve, B., Allan, A., Bertrand, G., Druzynska, E., Ertürk, A., Goldscheider, N., Henry, S., Karakaya, N., Karjalainen, T. P., Koundouri, P., Kupfersberger, H., Kvœrner, J., Lundberg, A., Muotka, T., Preda, E., Pulido-Velazquez, M. and Schipper, P.: Groundwater dependent ecosystems, Part II: Ecosystem services and management in Europe under risk of climate change and land use intensification, Environ. Sci. Policy, 14, 782-793, 2011 b.

Marttunen, M.: Interactive Multi-Criteria Decision Analysis in the Collaborative Management of Watercourses, Ph.D. thesis, Aalto University, Helsinki, Finland, 160 pp., 2011.

Marttunen, M. and Hämäläinen, R.: The Decision Analysis Interview Approach in the Collaborative Management of a Large Regulated Water Course, Environ. Manage., 42, 1026-1042, 2008. 
Marttunen, M. and Suomalainen, M.: Participatory and multiobjective development of watercourse regulation - creation of regulation alternatives from stakeholders' preferences, J. Multi-Crit. Decis. Anal., 13, 29-49, 2005.

Marttunen, M., Mustajoki, J., Dufva, M., and Karjalainen, T. P.: How to design and realize participation of stakeholders in MCDA processes? A framework for selecting an appropriate approach, EURO J. Decis. Process., 1-28, 2013.

McPhee, J. and Yeh, W.: Multiobjective Optimization for Sustainable Groundwater Management in Semiarid Regions, J. Water Resour. Pl. Manage., 130, 490-497, 2004.

Messner, F., Zwirner, O., and Karkuschke, M.: Participation in multi-criteria decision support for the resolution of a water allocation problem in the Spree River basin, Land Use Policy, 23, 63-75, 2006.

Munda, G.: Social Multi-Criteria Evaluation for a Sustainable Economy, Springer-Verlag, Berlin, 2008.

Mustajoki, J. and Hämäläinen, R. P.: Web-HIPRE: Global decision support by value tree and AHP analysis, INFOR, 38, 208-220, 2000 .

Mustajoki, J., Saarikoski, H., Marttunen, M., Ahtikoski, A., Hallikainen, V., Helle, T., Hyppönen, M., Jokinen, M., Naskali, A., Tuulentie, S., Varmola, M., Vatanen, E., and Ylisirniö, A.: Use of decision analysis interviews to support the sustainable use of the forests in Finnish Upper Lapland, J. Environ. Manage., 92, 1550-1563, 2011.

Pahl-Wostl, C., Holtz, G., Kastens, B., and Knieper, C.: Analyzing complex water governance regimes: the Management and Transition Framework, Environ. Sci. Policy, 13, 571-581, 2010.

Phillips, L.-D. and Phillips, M. C.: Faciliated Work Groups: Theory and Practice, J. Operat. Res. Soc., 44, 533-549, 1993.

Pykäläinen, J., Kangas, J., and Loikkanen, T.: Interactive decision analysis in participatory strategic forest planning: Experiences from state owned boreal, J. Forest Econom., 5, 341-364, 1999.

Qureshi, M. E. and Harrison, S. R.: A decision support process to compare Riparian revegetation options in Scheu Creek catchment in North Queensland, J. Environ. Manage., 62, 101-112, 2001.

Rauschmayer, F. and Wittmer, H.: Evaluation deliberative and analytical methods for the resolution of environmental conflicts, Land Use Policy, 23, 108-122, 2006.

Reed, M. S., Evely, A. C., Cundill, G., Fazey, I., Glass, J. H., Laing, A., Newig, J., Parrish, B., Prell, C., Raymond, C., and Stringer, L. C.: What is social learning?, Ecol. Soc., 15, http: //www.ecologyandsociety.org/vol15/iss4/resp1/ (last access: December 2013), 2010.

Regan, H., Davis, F., Andelman, S., Widyanata, A., and Freese, M.: Comprehensive criteria for biodiversity evaluation in conservation planning, Biodivers. Conserv., 16, 2715-2728, 2007.

Reichert, P., Schuwirth, N., and Langhans, S.: Constructing, evaluating and visualizing value and utility functions for decision support, Environ. Model. Softw., 46, 283-291, 2013.
Renn, O.: The Challenge of Integrating Deliberation and Expertise: Participation and Discourse in Risk Management, in: Risk Analysis and Society, An Interdisciplinary Characterization of the Field, edited by: McDaniels, T. and Small, M. J., Cambridge, Mass., 289-366, 2004.

Renn, O.: Participatory processes for designing environmental policies, Land Use Policy, 23, 34-43, 2006.

Rodela, R., Cundill, G., and Wals, A. E. J.: An analysis of the methodological underpinnings of social learning research in natural resource management, Ecol. Econ., 77, 16-26, 2012.

Rossi, P. M., Ala-aho, P., Ronkanen, A., and Kløve, B.: Groundwater-surface water interaction between an esker aquifer and a drained fen, J. Hydrol., 432-433, 52-60, 2012.

Salgado, P., Quintana, C. S., Pereira, A. G., del Moral Ituarte, L., and Mateos, B. P.: Participative multi-criteria analysis for the evaluation of water governance alternatives: A case in the Costa del Sol (Malaga), Ecol. Econ., 68, 990-1005, 2009.

Silva, V. S., Morais, D., and Almeida, A.: A Multicriteria Group Decision Model to Support Watershed Committees in Brazil, Water Resour. Manage., 24, 4075-4091, 2010.

Sparrevik, M., Barton, D. N., Oen, A. M., Sehkar, N. U., and Linkov, I.: Use of multicriteria involvement processes to enhance transparency and stakeholder participation at Bergen Harbor, Norway, Integr. Environ. Assess. Manage., 7, 414-425, 2011.

Straton, A., Jackson, S., Marinoni, O., Proctor, W., and Woodward, E.: Exploring and Evaluating Scenarios for a River Catchment in Northern Australia Using Scenario Development, Multi-criteria Analysis and a Deliberative Process as a Tool for Water Planning, Water Resour. Manage., 25, 141-164, 2011.

Turnhout, E., Hisschemöller, M., and Eijsackers, H.: Science in Wadden Sea policy: from accommodation to advocacy, Environ. Sci. Policy, 11, 227-239, 2008.

von Winterfeldt, D. and Edwards, W.: Decision Analysis and Behavioral Research, Cambridge University Press, Cambridge, 1986.

Wada, Y., van Beek, L. P. H., van Kempen, C. M., Reckman, J. W. T. M., Vasak, S., and Bierkens, M. F. P.: Global depletion of groundwater resources, Geophys. Res. Lett., 37, L20402, doi:10.1029/2010GL044571, 2010.

Weng, S. Q., Huang, G. H., and Li, Y. P.: An integrated scenariobased multi-criteria decision support system for water resources management and planning - A case study in the Haihe River Basin, Expert Syst. Appl., 37, 8242-8254, 2010.

Willis, R. and Liu, P.: Optimization Model for Ground-Water Planning, J. Water Resour. Pl. Manage., 110, 333-347, 1984.

Yang, Y. S., Kalin, R. M., Zhang, Y., Lin, X., and Zou, L.: Multi-objective optimization for sustainable groundwater resource management in a semiarid catchment, Hydrolog. Sci. J., 46, 55-72, 2001.

Yazicigil, H.: Optimal Planning and Operation of Multiaquifer System, J. Water Resour. Pl. Manage., 116, 435-454, 1990. 